\title{
GENDER DALAM KELUARGA BERENCANA (STUDI KASUS PARTISIPASI SUAMI DALAM MELAKUKAN KONTRASEPSI DI KELURAHAN MACANRE KECAMATAN LILIRILAU KABUPATEN SOPPENG)
}

\section{GENDER IN FAMILY PLANNING (CASE STUDY OF HUSBAND PARTICIPATION IN CONTRACEPTION IN MACANRE LILIRILAU SUBDISTRICT, SOPPENG)}

\author{
Nadyah ${ }^{1}$ Ahmad Afiif ${ }^{2}$ \\ Fakultas Kedokteran dan Ilmu Kesehatan UIN Alauddin \\ Fakultas Tarbiah dan Keguruan
}

\begin{abstract}
Family planning $(\mathrm{KB})$ is one of the government programs to reach a prosperous family by organizing or planning a pregnancy. KB is a means for families to plan the creation of an ideal family, a small, happy and prosperous family. Until now, family planning program in Indonesia has not paid attention to gender equality because in general the target of family planning services is dominated by women. Because of this condition, the purpose of this study is to describe the participation of husbands in the family planning program in this village of Macanre and know what affects the participation of husbands in the family planning program.

This type of study uses a descriptive method whereby data collection techniques are conducted with observations, documentation, and a deep interview to the community using sampling techniques with purposive sampling methods. The results were obtained indicating that in contraceptives the involvement of husbands in the village of Macanre very low. This condition is because it is based on the public belief that all responsibility in reproductive health is borne by women (wives), roles and reproductive functions related to the female body (wife) is the responsibility of women without human involvement (husband). People who are still closed and the taboo reproductive health problems are also a factor that causes the low role of husband to the reproductive health of the wife. Based on this, the need for guidance and education on reproductive health to the public is essential to increase knowledge and participation in family planning.
\end{abstract}

Keywords: family planning, gender discrimination, husband participation

\section{PENDAHULUAN}

Terciptanya keluarga yang sejahtera adalah harapan setiap keluarga. Salah satu cara yang dapat ditempuh untuk mewujudkan harapan tersebut dengan memastikan kesejahteraan keluarga yang salah satu caranya memperkecil jumlah anak sehingga mereka senantiasa merasa cukup. Tidak dapat dipungkiri bahwa

\footnotetext{
${ }^{1}$ Email : nadyaharuna@uin-alauddin.ac.id, Prodi Pendidikan Dokter UIN Alauddin

2 Email : ahmad.afiif@uin-alauddin.ac.id , Prodi Pendidikan Islam Anak Usia Dini UIN Alauddin
} 
jumlah anggota keluarga yang besar akan memberikan pembagi kebutuhan yang jumlahnya lebih besar tetapi dengan nominal yang lebih sedikit. Hal ini tentu saja berbeda dengan paradigma banyak anak adalah banyak rejeki yang untuk saat ini semakin disadari masyarakat bahwa jika banyak anak maka kebutuhan ekonomi mereka meningkat sehingga mereka harus bekerja keras lagi untuk pemenuhan kebutuhan. Tentu saja bahwa hal ini sejalan dengan program keluarga berecana yang memang merupakan salah satu program pemerintah. Keluarga berencana merupakan suatu proses pengaturan kehamilan agar terciptanya suatu keluarga yang sejahtera. Adapun menurut Undang Nomor 52 Tahun 2009 pasal 1 tentang Perkembangan Kependudukan dan Pembangunan Keluarga menyatakan bahwa bahwa Keluarga Berencana adalah upaya mengatur kelahiran anak, jarak dan usia ideal melahirkan, mengatur kehamilan melalui usaha promosi, perlindungan dan bantuan sesuai dengan hak reproduksi untuk mewujudkan keluarga berkualitas.

Undang - Undang Republik Indonesia Nomor 10 Tahun 1992 pasal 1 ayat 12 tentang perkembangan kependudukan dan pembangunan keluarga sejahtera menyatakan bahwa keluarga berencana adalah upaya peningkatan kepedulian dan peran serta masyarakat melalui pendewasaan usia perkawinan, pengaturan kelahiran, pembinaan ketahanan keluarga, peningkatan kesejahteraan keluarga untuk dapat mewujudkan keluarga kecil, Bahagia, dan sejahtera.

Partisipasi masyarakat dalam program Keluarga Berencana (KB) merupakan unsur penting untuk menekan laju pertumbuhan penduduk di Indonesia. Saat ini sasaran program KB lebih dominan pada perempuan. Alat-alat kontrasepsi yang ditawarkan oleh pemerintah lebih banyak digunakan oleh perempuan. Sebenarnya upaya untuk mengurangi angka kelahiran, bukan semata tanggung jawab perempuan, melainkan tanggung jawab kedua belah pihak yaitu suami dan istri. Isu ini sejalan dengan apa yang telah direkomendasikan di dalam konferensi internasional mengenai kependudukan dan pembangunan (International Conference on Populatin and Development = ICPD) di Kairo tahun 1994. Sesuai dengan kesepakatan ICPD serta sejalan dengan era globalisasi, reformasi dan demokratisasi yang menjadi paradigma universal saat ini, Program KB Nasional mempunyai komitmen yang tinggi pada upaya-upaya untuk memberdayakan kaum perempuan dimana 
perkembangan kependudukan dan pembangunan keluarga berdasarkan prinsip keadilan dan kesetaraan gender.

Berbagai upaya pembangunan nasional yang diarahkan untuk meningkatkan kualitas manusia, baik perempuan ataupun laki-laki, ternyata belum memberikan manfaat yang setara bagi perempuan dan laki-laki. Hal ini tidak saja berarti bahwa hakhak perempuan untuk memperoleh manfaat secara optimal dari pembangunan belum terpenuhi, tetapi juga karena masih belum termanfaatkannya kapasitas perempuan, sebagai sumber daya manusia, secara optimal. Di samping itu, rendahnya kualitas perempuan juga dapat mempengaruhi kualitas generasi penerusnya, mengingat bahwa mereka mempunyai fungsi reproduksi dan sangat berperan dalam mengembangkan sumberdaya manusia masa depan. Meskipun upaya meningkatkan kesetaraan dan keadilan gender telah menjadi salah satu sasaran Program KB Nasional, namun demikian dalam kenyataannya masih terdapat kebijakan dan program yang belum responsif gender. Di samping itu tumbuh anggapan yang kuat bahwa kaum perempuan/ibu bertanggungjawab pada urusan domestik, terutama dalam pengasuhan dan tumbuh kembang anak. Dalam kenyataannya, pelaksanaan program KB Nasional tidak akan terlepas dari pengaruh lingkungan yang ada.

Lingkungan yang belum searah dengan perkembangan program menuntut perlunya terus dilakukan penyesuaian-penyesuaian terhadap kebijakan yang ada. Beberapa hal penting yang dapat dirasakan berpengaruh terhadap kualitas pelaksanaan program keluarga berencana adalah masih dijumpainya kesenjangan dan permasalahan gender. Hal ini terlihat melalui kenyataan bahwa :

1. Jumlah penggunaan alat kontrasepsi pria masih rendah

Masih rendahnya pengggunaan alat kontrasepsi pada pria dapat dimungkinkan karena :

a) Terbatasnya jenis metode kontrasepsi bagi pria;

b) Kurangnya dukungan untuk pengemba- ngan metode kontrasepsi pria;

c) Rendahnya pengetahuan suami isteri tentang hak-hak reproduksi;

d) Kurangnya pengetahuan suami tentang keluarga berencana;

e) Lingkungan sosial budaya menganggap bahwa keluarga berencana dan kesehatan reproduksi merupakan urusan perempuan;

f) Terbatasnya informasi dan aksesibilitas pelayanan keluarga berencana dan 
kese- hatan reproduksi bagi pria.

2. Masih kurang terpenuhinya hak-hak reproduksi isteri selama ini dapat disebabkan oleh:

a) Kurangnya KIE hak-hak reproduksi bagi isteri;

b) Kurangnya kesempatan isteri untuk memperoleh informasi tentang hak-hak reproduksi;

c) Posisi isteri masih rendah dalam pengambilan keputusan keluarga berencana dan kesehatan reproduksi

d) Keterbatasan informasi mengenai hak-hak reproduksi suami istri

3. Istri cenderung dipersalahkan dalam hal ketidakpuasan hubungan seksual

4. Di dalam keluarga yang mengalami infertile istri cenderung menjadi pihak yang dipersalahkan

5. Penyakit Menular Seksual (PMS) yang diderita oleh istri dianggap bukan karena penularan suami

6. Masih kurangnya kepedulian dan kesadaran suami mengenai pencegahan dan penanggulangan HIV

7. Masih tingginya angka kematian maternal

8. Masih kurang memadainya fasilitas kesehatan keluarga berencana dan kesehatan reproduksi terutama untuk anak perempuan dan ibu.

Bahwa mewujudkan keluarga yang bahagia sejahtera merupakan tanggung jawab tidak saja pihak istri tetapi juga pihak suami serta berangkat dari masih banyaknya permasalahan berkaitan dengan ketidaksetaraan gender terutama dalam bidang kesehatan reproduksi maka peneliti tertarik untuk meneliti mengenai diskriminasi gender dalam keluarga berencana, studi kasus pada peran serta suami dalam melakukan kontrasepsi di Macanre Lilirilau Kabupaten Soppeng.

Terkait dengan latar belakang tersebut, maka penelitian ini bertujuan; mengetahui gambaran partisipasi suami dalam program keluarga berencana, halhal yang mempengaruhi partisipasi suami dalam mengikuti program keluarga berencana. Penelitian ini diharapkan bermanfaat sebagai data awal untuk penelitian selanjutnya, serta menjadi bahan dalam merubah pandangan mengenai keluarga berencana 


\section{METODE PENELITIAN}

Jenis penelitian yang digunakan dalam penelitian ini adalah penelitian deskriptif yang menggambarkan secara tepat mengenai sifat-sifat dan karakteristik suatu objek melalui pengumpulan dan penganalisaan data. Adapun teknik pengumpulan data yang dilakukan adalah dengan observasi, dokumentasi, dan wawancara mendalam kepada masyarakat dengan menggunakan teknik purposive sampling. Penelitian ini dilaksanakan pada tahun 2019 di Kecamatan Lilirilau yang terdiri dari 38.100 jiwa dengan 6013 Pasangan Usia Subur.

Populasi penelitian adalah keseluruhan jumlah objek penelitian atau objek yang akan diteliti (Notoatmodjo, 2012: 115). Berdasarkan pengertian populasi tersebut maka populasi dalam penelitian ini adalah semua Pria dari Pasangan Usia Subur yang ada di Kelurahan Macanre Kecamatan Lilirilau yang bersedia untuk menjadi responden adalah sebanyak 285 orang. Sedangkan Sampel adalah bagian dari jumlah dan karakteristik yang dimilikioleh populasi tersebut (Sugiyono, 2013: 81). Sampel penelitian adalah objek yang diteliti dan dianggap mewakili seluruh populasi (Notoatmodjo, 2012: 115). Dari 285 Pasangan Usia Subur yang bersedia untuk dijadikan sampel di Kelurahan Macanre 5 diantaranya tidak menjadi akseptor KB

Tabel 1

Distribusi Frekwensi Responden Berdasarkan Jenis Kontrasepsi Dan Yang Memotivasi ( $\mathrm{N}=285$ PUS)

\begin{tabular}{|c|c|c|c|c|c|c|}
\hline No & $\begin{array}{c}\text { Jenis } \\
\text { Kontrasepsi }\end{array}$ & Jmlh & $\%$ & Yang memotivasi & Jml & $\%$ \\
\hline 1 & Tubektomi & 2 & 0.714286 & Kesadaran sendiri & 228 & 81.42857 \\
\hline 2 & Kondom & 7 & 2.5 & \multirow[t]{2}{*}{ Suami } & \multirow[t]{2}{*}{13} & \multirow{2}{*}{4.642857} \\
\hline 3 & AKBK & 5 & 1.785714 & & & \\
\hline 4 & Suntik & 181 & 64.64286 & Petugas Kesehatan & 32 & 11.42857 \\
\hline 5 & IUD & 6 & 2.142857 & Pemerintah & 7 & 2.5 \\
\hline 6 & Pil & 76 & 27.14286 & \multirow[t]{2}{*}{ Tokoh Masyarakat } & & \\
\hline 7 & Implan & 3 & 1.071429 & & & \\
\hline \multicolumn{2}{|c|}{ TOTAL } & 280 & 100 & TOTAL & 280 & 100 \\
\hline
\end{tabular}

Sumber data : wawancara penduduk. 
280 PUS terdapat 5 orang yang tidak ber KB karena alasan tidak cocok, malas berKB, kurangnya pengetahuan, dll. Sedangkan 280 ber KB dengan macammacam alat kontrasepsi. Dari 280 orang PUS yang bersedia dan menandatangani persetujuan untuk menjadi sampel penelitian hanya 150 orang. Sampel dalam penelitian ini adalah sampel yang dipilih berdasarkan kriteria-kriteria tertentu yang didasarkan pada tujuan penelitian. Adapun yang menjadi kriteria pemilihan sampel adalah sebagai berikut:

a. Kriteria inklusi

1) PUS yang salah satu atau keduanya menjadi akseptor KB.

2) Bisa membaca dan menulis.

3) Bersedia menjadi responden.

b. Kriteria eksklusi

Responden yang tidak diambil dalam penelitian ini adalah sebagai berikut:

1) PUS yang tidak berdomisidi di Kelurahan Macanre

2) PUS yang tidak menjadi akseptor KB

3) PUS yang tidak bisa membaca dan menulis

4) Tidak bersedia menjadi responden

Sampel penelitian ditarik berdasarkan rumus :

$$
\begin{aligned}
& n=\frac{N}{N d^{2}+1} \\
& \text { Keterangan: } \\
& \text { n : Ukuran sampel } \\
& \mathrm{N} \quad \text { : Ukuran populasi } \\
& \text { d \& e : Tingkat kesalahan pengambilan sampel } \\
& \text { yang dapat ditolerir dengan kesalahan } 5 \% \text {. } \\
& n=\frac{150}{150(0,05)^{2}+1} \\
& n=\frac{150}{150(0,0025)+1} \\
& n=\frac{150}{0.375+1} \\
& n=\frac{150}{1,375} \\
& n=109,09 \\
& n=110
\end{aligned}
$$

Jadi yang menjadi sampel dalam penelitian ini adalah 110 orang. 
HASIL DAN PEMBAHASAN

Tabel 2

Distribusi Frekuensi Umur Responden

\begin{tabular}{|c|c|c|}
\hline $\begin{array}{c}\text { Umur } \\
\text { (Tahun) }\end{array}$ & Frekuensi & $\begin{array}{c}\text { Persentase } \\
(\%)\end{array}$ \\
\hline $16-20$ & 21 & 19.09091 \\
$21-25$ & 59 & 53.63636 \\
$26-30$ & 31 & 26.36364 \\
$\geq 31$ & 1 & 0.909091 \\
\hline Jumlah & 110 & 100 \\
\hline
\end{tabular}

Sumber: Data Primer

Responden yang bersedia untuk berpartisipasi di dalam penelitian ini berdasarkan kelompok umur didominasi oleh kelompok umur 21-25 tahun yaitu sebanyak 59 orang atau 53,63 \% dan kelompok umur terendah adalah di atas 31 tahun dengan persentase $0,9 \%$ (tabel 2).

Tabel 3

Distribusi Frekuensi Pendidikan Responden

\begin{tabular}{|c|c|c|}
\hline Pendidikan & Frekuensi & $\begin{array}{c}\text { Persentase } \\
(\%)\end{array}$ \\
\hline $\begin{array}{c}\text { Pendidikan Tinggi } \\
\text { Pendidikan Menengah } \\
\text { Pendidikan Dasar }\end{array}$ & 11 & 10 \\
\hline Jumlah & 17 & 74.54545 \\
& $\mathbf{1 1 0}$ & $\mathbf{1 0 0 \%}$ \\
\hline
\end{tabular}

Sumber: Data Primer

Mengacu kepada tingkat pendidikan mayoritas responden yang berpartisipasi di dalam penelitian ini adalah pada kelompok pendidikan menengah (SMP-SMA) yaitu sebanyak 82 orang atau 74,75\% (tabel 3)

Tabel 4

Distribusi Frekuensi Sikap Responden Tentang Penggunaan Alat Kontrasepsi Oleh Pasangan

\begin{tabular}{|c|c|c|}
\hline Sikap & Frekuensi & $\begin{array}{c}\text { Persentase } \\
(\%)\end{array}$ \\
\hline Positif & 30 & 27,27 \\
Negatif & 80 & 72,73 \\
\hline Jumlah & 110 & $100 \%$ \\
\hline
\end{tabular}

Sumber: Data Primer 
Tabel 4 menunjukkan distribusi sikap responden mengenai penggunaan alat kontrasepsi oleh pasangan. Dukungan penggunaan kontrasepsi adalah sikap positif dimana dalam penelitian ini hanya 30 atau 27,27 \% responden yang menunjukkan sikap positif/dukungan pada pasangannya di dalam menggunakan alat kontrasepsi.

Tabel 5

Distribusi Frekuensi Kesediaan Responden Untuk Menggunakan Alat Kontrasepsi

\begin{tabular}{|c|c|c|}
\hline Pekerjaan & Frekuensi & $\begin{array}{c}\text { Persentase } \\
(\%)\end{array}$ \\
\hline Bersedia & 7 & 6,37 \\
Tidak & 103 & 93,63 \\
\hline Jumlah & 110 & $100 \%$ \\
\hline
\end{tabular}

Sumber : Data Primer

Tabel 5 menunjukkan bahwa terdapat 103 peserta atau 93.3\% responden dalam penelitian ini ternyata tidak bersedia menggunakan alat kontrasepsi pria dan hanya 7 orang atau $6.37 \%$ responden yang bersedia menggunakan kondom (alat kontrasepsi pria) meskipun dalam penggunaannya responden tidak konsisten di dalam penggunaan alat kontrasepsi pria.

Berdasarkan hasil penelitian menunjukkan dukungan suami terhadap penggunaan alat kontrasepsi ada tetapi menunjukkan hanya 4,64\% (tabel 1) yang menunjukkan dukungan penuh pada pasangan untuk menggunakan dan memilih alat kontrasepsi. Hal ini dapat terjadi karena masih kurangnya pengetahuan responden tentang jenis kontrasepsi terutama terkait vasektomi sebagai konstrasepsi pilihan. Pernyataan tersebut sama dengan penelitian Purwoko (2000) pengetahuan menyumbangkan peran dalam menentukan pengambilan keputusan untuk memilih alat kontrasepsi tertentu. Semakin tinggi tingkat pengetahuan tentang alat kontrasepsi, maka makin meningkat pula perannya sebagai pengambil keputusan.

Dari 110 responden dalam penelitian ini terlihat bahwa 72,3\% (tabel 4) responden masih menunjukkan adanya sikap negatif mengenai penggunaan alat 
kontrasepsi oleh pasangan. Meskipun responden memperbolehkan pasangannya untuk menjadi akseptor KB tetapi anggapan bahwa KB menjadi tanggung jawab pihak istri masih dominan di kalangan responden. "KB itu urusannya ibu-ibu kalo bapak yah kerja cari uang untuk makan, untuk anak-anak sekolah"3 pendapat senada mengemukakan bahwa "kenapa bapak-bapak lagi yang harus urus kalo ibu pake KB yang penting semua tau tugasnya masing-masing saja". 4 Adapula responden yang mengatakan "hamil, melahirkan yah ibu jadi dia yang harus mengatur dan menjaga badannya". ${ }^{6}$ Beberapa responden memberikan dukungan pada pasangannya tetapi dalam kenyataan perubahan fisik pasangan menjadi lebih gemuk, atau perdarahan yang memanjang menjadi keluhan yang tidak menyenangkan buat responden. Ada responden yang berpendapat bahwa "tidak apa-apa ibu ikut KB karena jaman sekarang apa-apa semua serba mahal"5 ada juga yang menyatakan "sepertinya ibu tidak cocok dengan KB nya karena sejak pake KB kalau datang sakit bulan-bulannya lama sekali lamaki juga puasa"6

Ketidaknyamanan karena efek alat kontrasepsi pada tubuh pasangan (perubahan bentuk tubuh, wajah berjerawat, dan perdarahan yang memangjang) sayangnya tidak disertai dengan toleransi dari responden untuk menggunakan alat kontraseps bagi pria, dari 122 responden 118 atau 96,8 \% tidak bersedia untuk menggunakan alat kontrasepsi. Hal ini disebabkan karena rasa tidak nyaman ketika melakukan coitus, selain itu penggunaan alat kontrasepsi dirasakan kurang praktis karena harus dipasang dan dilepaskan setelah melakukan coitus. "tidak enak rasanya seperti ada yang mengganjal"7 Beberapa responden juga masih ada yang kurang memahami cara yang tepat di dalam menggunakan alat kontrasepsi bagi pria "itu kadang ada yang bocor juga, terus kalo ketemu mamaknya anak-anak tidak enak kalau pakai kondom karena musti dipasang pas kita sudah mau enak"8

Dari penelitian ini dapat dilihat adanya korelasi antara tabel 4 dan tabel 5 terkait sikap responden dalam penggunaan alat kontrasepsi. Penggunaan alat

\footnotetext{
3 Tn. M, petani

4 Tn. RI, petani

5 Tn. B, PNS

${ }^{6} \mathrm{Tn} . \mathrm{K}$, petani

${ }^{7}$ Tn H. N, tokoh masyarakat (PNS)

8 Tn.AA Pegawai
} 
kontrasepsi merupakan bentuk perilaku seseorang yang didasari penilaian positif pada kegiatan tersebut, baik dengan tujuan tertentu maupun sekedar mengikuti lingkungannya. Hal tersebut menekankan pentingnya sebuah niat dan pemikiran yang positif terhadap perilaku seseorang. Fishben dan Ajzein menyebutkan bahwa keyakinan akibat perilaku merupakan pengetahuan yang berasal dari diri sendiri yang positif maupun negatif. Dari hal tersebut akan menghasilkan sikap yang selanjutnya akan menumbuhkan minat seseorang untuk melakukan perilaku tertentu. Oleh karena itu sangat diperlukan sosialisasi KB bagi pria karena hal ini masih menjadi barang langka, jarang dan sulit ditemui di masyarakat, sehingga metode KB pria seperti vasektomi dan kondom masih belum sepopuler metode kontrasepsi wanita seperti pil, suntik, atau IUD. Untuk dapat mendukung sosialisasi program KB pria diperlukan adanya promosi dan motivasi dari kaum pria yang telah menjadi akseptor KB pria. Apalagi bila para akseptor tersebut telah bergabung dalam suatu kelompok KB. Dengan terbentuknya kelompok KB pria tersebut maka proses sosialisasi KB pria ke masyarakat akan lebih mudah dan menjadi lebih terarah.

Selain kurangnya sosialisasi kendala yang paling sering menghampiri pasangan dalam rumah tangga adalah soal minimnya komunikasi. Masalah komunikasi dua pribadi yang berbeda, jika disatukan tanpa perekat yang kuat berupa komunikasi yang kuat pula, akan menimbulkan berbagai masalah, termasuk diantaranya ketidaktahuan akan pemenuhan hak dan kewajiban reproduksi yang harus dilakukan suami. Selain itu komunikasi mengenai kesehatan reproduksi hendaknya tidak menjadi hal yang tabu di dalam masyarakat. Meningkatkan peran pria dalam program KB tidak bisa dilakukan hanya secara parsial saja, hanya sekedar mengajak atau mensosialisasikan cara dan alat KB saja, tapi harus secara menyeluruh dengan menggali segala akar permasalahannya untuk merubah pola pikir bahwa reproduksi juga merupakan tanggung jawab laki-laki. Kesertaan KB bagi pria tidak bisa ditunda-tunda lagi, karena kesertaan pria dalam program KB akan memberikan kontribusi yang sangat besar terhadap upaya pengendalian laju pertumbuhan penduduk dan penanganan masalah kesehatan reproduksi termasuk penurunan angka kematian ibu melahirkan maupun angka kematian bayi, yang kesemuanya itu mempunyai 
pengaruh cukup besar dalam upaya meningkatkan kualitas sumber daya manusia (SDM).

Di Indonesia vasektomi tidak termasuk dalam program keluarga berencana nasional. Vasektomi merupakan tindakan pemotongan vas deferens melalui operasi dengan anestesi lokal. Pada dasarnya indikasi untuk melakukan vasektomi ialah bahwa pasangan suami-istri tidak menghendaki kehamilan lagi dan pihak suami bersedia dilakukan tindakan kontrasepsi pada dirinya. Keterbatasan pilihan methode kontrasepsi pria dan ketersediaan dukungan jaringan pelayanan Keluarga Berencana dan Kesehatan Reproduksi. Meskipun dari dua methode KB pria telah tersedia berbagai merek kondom dan telah dikembangan beberapa tehnik vasektomi yang relative lebih baik, namun seringkali menjadi alasan utama yang dikemukakan dari berbagai pihak, mengapa kesertaan pria dalam KB rendah.

Aksesabilitas Pelayanan dan dukungan jaringan pelayanan Keluarga Berencana dan Kesehatan Reproduksi Remaja bagi Pria masih sangat terbatas. Aksesabilitas informasi Keluarga Berencana dan Kesehatan Reproduksi baik media KIE, Konseling yang tersedia, informasi yang diberikan oleh petugas, tempat pelayanan yang ada masih bias gender. Agama juga sering kali digunakan sebagai alasan untuk menolak penggunaan alat kontrasepsi. Persoalan yang paling penting dan kadang diperdebatkan dalam Islam mengenai KB adalah soal penentuan jumlah anak. Ada sebagian kalangan yang menilai membatasi kelahiran dengan alasan takut tidak bisa menghidupi anak, tidak dibenarkan dalam Islam. Dalam pandangan Islam sebagaimana difatwakan oleh Majelis Ulama Indonesia (MUI) pada Musyawarah Nasional MUI tahun 1983, KB dinilai sebagai suatu ikhtiar atau usaha manusia untuk mengatur kehamilan dalam keluarga secara tidak melawan hukum agama, Undang-Undang (UU) Negara dan moral Pancasila, Agama Islam membenarkan pelaksanaan KB untuk menjaga kesehatan ibu dan anak.

Masih rendahnya pengetahuan orang tua dan remaja tentang kesehatan reproduksi; prioritas utama untuk memperoleh pendidikan tetap pada anak laki-laki; rendahnya kepedulian remaja laki-laki daiam kegiatan Kesehatan Reproduksi Remaja (KRR) serta manfaat kegiatan KRR kurang dirasakan oleh remaja laki-laki seharusnya menjadi perhatian. Keterkaitan antara usia dan tingkat pendidikan dengan kurangnya pengetahuan mengenai kesehatan reproduksi di dalam penelitian ini 
juga terlihat bahwa dari responden yang memberikan sikap negatif adalah semua reponden dengan tingkat pendidikan dasar sebagian besar adalah mereka dengan pendidikan menengah namun ditemukan pula responden dengan pendidikan tinggi yang masih memberikan adanya sikap negatif. Kurangnya pengembangan metode kontrasepsi pria, yang mengakibatkan terbatasnya jenis/metode kontrasepsi pria; informasi tentang peran suami dalam KB/KR masih kurang yang mengakibatkan pengetahuan suami tentang metode $\mathrm{KB}$ pria dan kesehatan reproduksi relatif rendah untuk kasus ini tingkat pendidikan dan pekerjaan tidak menjadi jaminan hal ini karena di dalam kenyataannya suami/pria masih mengedepankan kenyamanannya sendiri; selain factor tersebut terbatasnya tempat pelayanan $\mathrm{KB} / \mathrm{KR}$ bagi kaum pria; adanya kondisi suami cenderung tidak merasa bersalah dalam ketidakpuasan hubungan seksual dan infertilitas; rendahnya kesadaran suami tentang pencegahan PMS, IMS dan HIV/ AIDS; rendahnya keterlibatan suami dalam pemeliharaan kelangsungan hidup ibu, bayi dan anak serta keterbatasan informasi bagi laki-laki/suami tentang pemeliharaan kelangsungan hidup ibu, bayi dan anak tentu menjadi perlu perhatian disamping perlunya para penentu kebijakan, pengelola dan pelaksana program untuk mengoptimalkan program agar tidak sensitif gender.

\section{SIMPULAN DAN SARAN}

Partisipasi suami/ pria dalam keluarga berencana memang masih rendah hal ini disebabkan karena hingga saat ini kontrasepsi lebih banyak diperuntukkan untuk perempuan. Peningkatan partisipasi KB Pria masih perlu mendapatkan perhatian, utamanya dalam memberikan pemahaman bahwa KB bukan hanya domainnya perempuan dalam penanaman nilai-nilai sikap, budaya, persepsi dan pengetahuannya tentang KB Pria sejalan dengan tuntutan kesetaraan dan keadilan gender. Keluarga Berencana yang berkeadilan gender diperlukan mulai dari pemilihan jenis kontrasepsi, keikutsertaan dalam ber KB juga dukungan di dalam menghadapi efek samping penggunaan alat kontrasepsi. Kemudian perlunya penambahan SDM Penyuluh KB dan peningkatan sarana dan prasarana media sosialisasi dan penyuluhan KB Pria, terakhir dukungan istri menjadi motivasi utama dalam mendukung suami untuk berKB, selain karena alasan kesehatan reproduksi yang menjadi tanggung jawab suami dan istri. Kondisi masyarakat yang 
masih tertutup dan menganggap tabu masalah kesehatan reproduksi juga menjadi faktor yang menyebabkan masih rendahnya peran suami terhadap kesehatan reproduksi istri sehingga perlu adanya pembinaan dan pendidikan kesehatan reproduksi kepada masyarakat untuk meningkatkan pengetahuan dan partisipasi dalam berkeluarga berencana.

\section{DAFTAR PUSTAKA}

Azwar, Azrul. Kebijakan dan Strategi Nasional Kesehatan Reproduksi di Indonesia. Dirjen Bina Kesehatan Masyarakat. Jakarta. 2005. 2.

Badan Pusat Statistik (BPS). 2013. Survei Demografi dan Kesehatan Indonesia Tahun 2012. Jakarta.

BAPPENAS. 2002. Analisis Gender dalam Pembangunan Keluarga Berencana Nasional Aplikasi Gender Analysis Pathway (GAP) dan Berbagi Pengalaman. Jakarta

Bertrand. Kerangka Pikir Konseptual Permintaan KB serta Dampak Pada Fertilitas. Dalam : BKKBN. Peningkatan Akses dan Kualitas Pelayanan KB. BKKBN. Bandung. 2007.

BKKBN. 2012. Materi Pegangan Kader Tentang Bimbingan dan Pembinaan Keluarga Remaja. Jakarta

BKKBN. Fakta, Data dan Informasi Kesenjangan Gender di Indonesia. BKKBN.Jakarta. 2001.

BKKBN. Faktor-Faktor yang mempengaruhi Rendahnya Partisipasi Pria dalam KB. http://www.bkkbn.go.id/gemapria/info-detail.php?infid=79. 2007. 23.

BKKBN. Peningkatan Akses dan Kualitas Pelayanan KB. BKKBN. Bandung.

BKKBN. Peningkatan Partisipasi Pria dalam Keluarga Berencana dan Kesehatan Reproduksi di Indonesia. http://www.bkkbn.go.id/diftor/download.php?. 2003.

Dwijayanti, Riski. Analisis Respon Masyarakat Desa terhadap Program KB dalam Rangka Peningkatan Kualitas Sumber Daya Manusia di desa Cihideung Udik kabupaten Bogor. http://dikti.go.id/pkm/pkmi-award2006/pdf/pkmi06-016.pdf.

Endang. Buku Sumber Keluarga Berencana, Kesehatan Reproduksi, Gender, dan Pembangunan Kependudukan. BKKBN \& UNFPA. Jakarta. 2002.

Hartanto. Keluarga Berencana dan Kontrasepsi. Pustaka Sinar Harapan. Jakarta. 2003.

Heru. KB Distribusi Pemerintah. http://Pikas.bkkbn.go.id/new.detail.php?nid.

Manuaba. Ilmu Kebidanan, Penyakit Kandungan, \& Keluarga Berencana untuk Pendidikan Bidan. EGC. Jakarta. 1998. 21.

Safrudin et.al. 2009. Kebidanan Komunitas. Buku Kedokteran EGC: Jakarta

Silalahi, Karlinawati, dan Eko A. Meinarno. 2010. Keluarga Indonesia Aspek Dinamika Zaman. Jakarta

Siswosudarmo, HR. dkk. 2007. Teknologi Kontrasepsi. Yogyakarta; Gadjah Mada University Press. 
Sugiyono. Statistik untuk Penelitian. Alfabeta. Bandung. 2002. 6. Satria, Yurni. Isu Gender dalam Kesehatan Reproduksi. Pusat Pelatihan Gender dan Peningkatan Kualitas Perempuan BKKBN. Jakarta. 2005. 7. BKKBN. Gender dalam Program KB dan KR. http://gemapria.bkkbn.go.id/artikel02-2I.html.

Syaifudin. Buku Panduan Praktis Pelayanan Kontrasepsi. Yayasan Bina Pustaka Sarwono Prawirohardjo. Jakarta. 2003.

Undang-Undang Republik Indonesia Nomor 10 Tahun 1992 tentang perkembangan kependudukan dan pembangunan keluarga sejahtera. http://birohukumsiskum.sumutprov.go.id/myadmin/undang/10\%20Tahun\% 201992.pdf.

Wijayanti, Titik. Studi Kualitatif Alasan Akseptor Laki-Laki tidak Memilih MOP sebagai Kontrasepsi Pilihan di desa Timpik kecamatan Susukan kabupaten Semarang. Program Studi D IV Kebidanan Stikes Ngudi Waluyo. Ungaran. 2004.

Wiknjosastro, H. Ilmu Kebidanan. Yayasan Bina Pustaka Sarwono Prawirohardjo. Jakarta. 1999.Azis, Mustafa. 2009. Untaian Mutiara Keluarga : Bekal Keluarga dalam Menapaki Kehidupan. Yogyakarta; Mitra Pustaka 